\title{
О ПСИХОЛОГИЧЕСКИХ МЕХАНИЗМАХ ПОВЫШЕНИЯ ЭФФЕКТИВНОСТИ ДЕЯТЕЛЬНОСТИ ПЕРСОНАЛА В ОРГАНИЗАЦИИ
}

\author{
Е. М. Иванова \\ Московский государственный университет имени М.В. Ломоносова, г. МоскВа, Российская Федерация
}

\section{ИНФОРМАЦИЯ О СТАТЬЕ}

Дата поступления

4 апреля 2016 г.

Дата принятия к печати 23 августа 2016 г.

Дата онлайн-размещения 28 декабря 2016 г.

\section{КАЮЧЕВЫЕ СЛОВА}

Профессиональная деятельность, персонал, эффективность, психологические механизмы, познавательная деятельность

\begin{abstract}
АННОТАЦИЯ
Статья посвящена психологическому аспекту проблемы эффективности профессиональной деятельности персонала в организации и ее решению в зарубежной и отечественной науке и практике. Эффективность труда в зарубежной науке рассматривается во взаимосвязи с концепцией «человека постмодерна». Данное представление уже ориентировано на творчество, свободу и ответственность за самого себя. Представлены общие психологические принципы изучения и применения механизмов повышения эффективности профессионального труда. Характерной особенностью зарубежных работ является прагматизм, базирующийся на практике как критерии истины и личностной значимости. Для отечественных научно-практических исследований характерна тенденция построения работы с методологических позиций на основе теоретических концепций и эмпирических исследований психического развития человека как личности и формирования как субъекта труда. В статье представлена оригинальная технология изучения, формирования и оценки психологических механизмов регуляции эффективностью профессиональной деятельности человека, построенная с позиций системно-деятельностного подхода. Данный подход к изучению, формированию и оценке сформированности психологических механизмов эффективности профессиональной деятельности можно рассматривать как ориентировочную основу совершенствования управления эффективностью труда персонала в организации. Изменения иерархических взаимосвязей компонентов структуры познавательной деятельности и их направленность, преобладание развития каких либо психических сфер и соответствие этого развития объективной ситуации в которой оказывается человек, доминирующая активизация различных психических сфер в разных фазах (ориентировочной, исполнительной и продуктивной преобразующей) осуществления деятельности на разных этапах профессионального становления, могут быть ориентирами и показателями для определения проекта и программы решения различных практических задач в целях повышения эффективности деятельности персонала в организации.
\end{abstract}

\section{ABOUT THE PSYCHOLOGIC MECHANISMS OF THE EFFECTIVENESS IMPROVEMENT OF THE CORPORATE STAFF}

\author{
Elena M. Ivanova \\ Lomonosov Moscow State University, Moscow, Russian Federation
}

\section{ARTICLE INFO}

Received

April 4, 2016

Accepted

August 23, 2016

Available online

December 28, 2016

\section{KEYWORDS}

Professional activities, staff, effectiveness, psychological mechanisms, cognitive activity

\begin{abstract}
The article touches upon the theme of psychological aspect of the corporate staff professional activity effectiveness problem and its solution in Russian and foreign science and practice. Labor effectiveness is taken in conjunction with "postmodern man» conception in foreign literature. This concept is already focused on creativity, freedom and self-responsibility. The article shows common psychological principles of studying and using professional activity effectiveness improvement mechanisms. Foreign papers can be characterized by pragmatism that is based on practice as the criteria of truth and personal importance. On the other hand, Russian works are characterized by importance of methodological based on theoretic conceptions and empiric studies of human psychological development as a person and forming of a subject of labor. The article offers a special technology of studying, forming, and evaluation of psychological mechanisms of
\end{abstract}


human professional activity effectiveness regulation, based on systems-activity approach. This approach can be considered as model basis of improvement of the corporate staff labor effectiveness management. Alteration of hierarchical interrelations of cognitive activity structural components and their focus, domination of some psychological spheres development corresponded to objective situation in which the person acts, predominant activation of various psychological spheres in various phases (tentative, conscientious, and productive-modifying) of the activities implementation on different stages of professional development can determine the project and various practical tasks programs with the aim of corporate staff activity effectiveness improvement.

Проблема эффективности профессиональной деятельности включает разные, но взаимосвязанные аспекты: социальные, экономические, технические, социальнопсихологические, психофизиологические, организационные и психологические. Это престижность и востребованность профессии в обществе и в организации, ее экономическая обеспеченность, организационно-экологическая культура труда, профессиональные функциональные взаимосвязи персонала, напряженность труда. Каждый из названных аспектов или их совокупность можно рассматривать как факторы, обусловливающие эффективность деятельности индивидуального и коллективного субъекта труда, с объективной и с субъектной точек зрения. Именно они могут влиять на интерес человека к профессии, потребность в профессиональном развитии и самореализации, карьерном росте, его отношении к работе, к коллегам, к организации, а также - влиять на его мотивационно-ценностную направленность.

В научной и практической области знания проблема эффективности профессионального труда стала одним из центральных аспектов управления персоналом в организации со второй половины XIX в., сначала за рубежом. Начинают разрабатываться теории, модели управления персоналом в целях поиска психологических способов и форм регуляции повышения экономической эффективности деятельности работников в организации. Исходной позицией в работах зарубежных ученых явилось представление об отношении человека к труду в разные периоды социального, технического и экономического развития общества, на основе которого разрабатывались теории и концепции управления эффективностью профессионального труда. В качестве основного психологического механизма воздействия рассматривалась мотивация, побуждающая человека выполнять свою работу с наибольшей отдачей и быть удовлетворенным. Первоначально рассматривалось только материальное стимулирование труда. Постепенно, в XX в. расширились представления ученых о механизмах психологического воздействия на эффективность профессионального труда и мотивационно-потребностная сфера стала рассматриваться во взаимосвязи с коммуникативной, когнитивной и эмоционально-регуляторной. Хронологическая и содержательная динамика этих изменений детально раскрыта в работе немецких ученых, выделивших специфические особенности представлений о человеке, обусловивших и формы управления эффективностью труда персонала в организации [1]. Так представление о «человеке экономическом» рассматривалось во взаимосвязи с мотивом максимальной выгоды работника, так как фокус мотивации был сконцентрирован на результате, а не на содержании труда. Представление о «человеке социальном», в первую очередь, рассматривалось во взаимосвязи с социальными мотивами, обусловленными межличностными отношениями, наряду с материальными потребностями. В представлении о «человеке самоактуализирующемся» выделялась, как основная, взаимосвязь с мотивом самореализации в профессиональной деятельности. В представлении о «человеке комплексном» рассматривались взаимосвязи с разными мотивами и потребностями, представляющими комплекс внешних и внутренних мотивов, обусловливающих индивидуальное восприятие человеком реальной ситуации и эффективность профессиональной деятельности. Именно в представлении о «человеке комплексном» интегрируются все механизмы регуляции, применявшиеся при экономическом, социальном и самоактуализирующемся типах управления эффективностью труда [1, с. 178]. В конце $\mathrm{XX}$ в. появляется представление о «постмодернистическом человеке» [Там же, с. 247]. Данное представление уже ориентировано на творчество, свободу и ответственность за самого себя. Механизмами регуляции успешной и 
эффективной профессиональной деятельности становятся потребности в саморазвитии, самореализации и такие ценности как свобода и автономия, что в условиях современных перемен рассматривается как важнейшие качества персонала организации.

Наряду с научными теориями, концепциями и представлениями о психологических механизмах повышения эффективности профессиональной деятельности человека в зарубежной практике разработаны и оригинальные технологии управления персоналом «постмодернистического типа», так как современные условия функционирования организации требуют динамического развития специалистов, посредством их активного участия в «жизни» всей организации, ее развитии и конкурентноспсобности. В этих технологиях применяются разные психологические механизмы совершенствования деятельности и оценки современных специалистов и как профессионалов [2], и как высокоэффективных саморазвивающихся и самореализующихся людей [3], а также, как стратегов собственной деятельности и профессионального будущего [4]. Так Д. Майстер важнейшим показателем успеха считает отношение к делу, к коллегам, интерес и гордость за свою работу, а также дисциплинированность, обязательность, увлеченность, стремление к совершенствованию и превыше всего - энтузиазм, которые он считает основой эффективной работы персонала. Технология Стивена Р. Кови раскрывает основные принципы формирования высокоэффективных людей, с позиций динамики развития и саморазвития человека в процессе его жизнедеятельности и профессиональной деятельности, как осознаваемое существование в окружающем мире: «в мире все взаимосвязано, но все достижения человека невозможны без взаимодействия с окружающими людьми - человеческой жизни присуща взаимозависимость» [3, с. 54] Он выделяет навыки, которые трактует как принципы человеческой эффективности (проактивность, персональное видение, персональное лидерство, персональное управление, межличностное лидерство, творческое сотрудничество и др.) так как, по его мнению, они являются основополагающими в развитии персональной и межличностной эффективности и обусловливают постепенное формирование способности человека к самореализации, самосовершенствованию и продуктивному межличностному взаимодействию. Причем эти принципы он рассматривает с позиций объективной и субъективной реальности. «Объективная реальность» - это «маяки», естественные законы взаимоотношений людей в обществе; справедливость, честность, искренность, человеческое достоинство, служение обществу, ответственность, полезность и т. п. «Субъективную реальностью» Стивен Р. Кови называет «картой», предопределяющей поведение человека, его ориентацию в ситуации. Это представление, образ окружающей реальности, ее восприятие, понимание, толкование [5, с. 27]. «В своей жизни и в своих взаимоотношениях люди видят только то, что предопределено «картами», созданными их опытом и условиями существования» [3, с. 38]. Основная идея технологии Стивена Р. Кови заключается в инструментальном обеспечении условий для последовательного формирования базовых механизмов регуляции, обеспечивающих эффективную жизнедеятельность и профессиональную деятельность человека. В качестве критерия эффективности он рассматривает «баланс», равновесие между желаемым результатом, ресурсами и средствами, позволяющими его достичь [3, с. 59]. К психологическим ресурсам эффективной регуляции деятельности он относит личностные ценности, ощущения, способность к самоконтролю, отношение, воображение, самосознание, ответственность, интересы, цели, самоуправление, инициативность, мотивацию, дисциплинированность, волевую регуляцию, осознание своего жизненного предназначения, эмоциональность, взаимоотношения между людьми.

В концепции управления развитием и переменами Хьюберта К. Рамперсада, которую он называет универсальной системой показателей деятельности, рассматривается взаимосвязь совершенствования управления деятельностью людей в организации с индивидуальным самосовершенствованием как отдельных работников, так и коллективной деятельности персонала организации. Применение в практике данной концепции направлено на формирование готовности сотрудников организации к переменам, посредством циклического процесса обучения, обеспечивающего саморазвитие, самопознание, мобилизацию творческих способностей, т. е. предполагающее максимальное разви- 
тие личности сотрудников всей организации (компании). Основными психологическими механизмами управления деятельностью персонала в организации и их развитием, т. е. «точкой отсчета концепции», является «восприятие человеком своей индивидуальности», личное видение сотрудниками своего будущего и общая мечта о будущем организации, цели личности, личностные устремления сотрудников [4, с. 14-15]. В то же время в концепции Хьюберта К. Рамперсада рассматривается и взаимосвязь перемен в организации с личностными переменами сотрудников организации: «успех организационных перемен и развития организации возможен лишь в случае достижения баланса между тремя основополагающими элементами...»: совершенствованием, развитием и обучением [Там же, с. 31].

Анализ и обобщение рассмотренных теоретических и практических работ зарубежных специалистов, направленных на совершенствование технологии управления человеческими ресурсами в организации в целях повышения успешности, и, как следствие, экономической эффективности профессиональной деятельности персонала, позволило выявить целый ряд общих психологических принципов изучения и применения механизмов повышения эффективности профессионального труда с взглядами отечественных ученых на решение данной проблемы. Этими принципами являются: динамическое развитие человека в процессе жизнедеятельности и профессиональной деятельности, его совершенствование и обучение; управление регуляцией профессиональной деятельности и поведением во взаимосвязи с особенностями перемен в организации, а так же формирование сбалансированной системы их взаимосоответствия; выделение основных психологических механизмов саморегуляции профессиональной деятельности: представления («карты» - «образы») отношение (мотивы, интересы, цели, ценности); осознание, самопознание, самоценка, саморегуляция и др. Основное отличие зарубежных и отечественных работ заключается в разных «философских воззрениях» на научные подходы к решению проблемы повышения эффективности деятельности персонала в организации. Характерной особенностью зарубежных работ является прагматизм, базирующийся на практике как критерии истины и личностной значимости. Для отечественных на- учно-практических исследований наиболее характерна тенденция построения работы с методологических позиций на основе теоретических концепций и эмпирических исследований психического развития человека как личности и формирования как субъекта труда. Методологической основой исследования является системно-деятельностный подход, на основе которого рассматриваются субъектно-объектные взаимосвязи человека с объективной реальностью: личностные, эмоциональные, операциональные, функциональные, субъектные, динамические и др., проявляющиеся в деятельности на разных этапах психического и профессионального развития человека

В настоящее время, в нашей стране актуальной стала проблема «распределенного управления» индивидуальным и коллективным субъектом труда во взаимосвязи со спецификой структуры конкретной организации. В условиях распределенного управления человеческими ресурсами, в качестве инструмента повышения эффективности профессиональной деятельности всех субъектов конкретной организации, становится концепция распределенного познания, распределенного профессионального знания о целях, необходимой направленности, способах и средствах действий, критериях результативности [6]. В этих условиях, наряду с профессиональными знаниями, умениями и мотивационно-ценностной направленностью на успешное исполнение работы, необходима ориентация не только в реальном процессе труда, но и в перспективах возможных перемен в организации и собственной профессиональной деятельности. Характерной особенностью современного развития организаций является непредсказуемость и быстротечность происходящих перемен, требующих психологической готовности персонала. Это с одной стороны, приводит к необходимости по-новому определять смысл и сущность профессии для человека, его функции, роль и статус в производственных, социальных и управленческих процессах в организации в целях повышения эффективности функционирования организации и сохранения конкурентноспособности, а также, удовлетворенности и безопасности деятельности каждого специалиста. С другой стороны многоплановость объективной реальности, разнообразие видов профессионального труда, трудовых постов и должностных статусов, 
практических задач, их инновационность, а главное - индивидуальное своеобразие человека как личности и субъекта труда (его мировосприятие, отношение, представление, осознание, переживание, психическое развитие, функциональные возможности организма и профессиональная готовность), которые необходимо рассматривать во взаимосвязи, требуют по - новому рассматривать психологические механизмы повышения эффективности деятельности персонала организации.

Направляющей линией определения психологических механизмов, предопределяющих эффективность профессиональной деятельности персонала, в данной работе, являются методология системного исследования, принцип развития и деятельностный подход. Системный подход к психологическому исследованию Э.Г. Юдин рассматривает как принцип, руководящий общей стратегией научного познания [7, с. 51]. Причем, если понятие системы как целостности «выполняет по преимуществу стратегически-ориентирующую роль в системном исследовании, то понятие связи выступает обычно и в качестве средства исследования» [Там же, с. 187]. Принцип развития трактуется А. Г. Асмоловым как «система отсчета, в координатах которой раскрываются все остальные принципы анализа процессов психического отражения действительности» человеком в процессе его жизнедеятельности [5, с. 11]. В реальности, «в жизни каждого человека присутствуют последовательные стадии роста и развития», «каждый шаг важен и требует времени, и не один не может быть пропущен» [3, с. 40]. Развитие человека как личности и субъекта труда представляет собой непрерывный динамический процесс, проявляющийся в разных видах деятельности (познавательной, учебной преобразующей, профессиональной), который охватывает все периоды жизни человека от младенчества до глубокой зрелости.

Деятельность рассматривается как категория психологического познания, как единица жизни телесного материального субъекта, опосредованная психическим отражением, реальная функция которого состоит в том, что оно ориентирует субъекта в предметном и социальном мире [8].Деятельность - это «исходная ситуация развития человека, так как в онтогенезе она представляет «систему сменяющих друг друга деятельностей или чередующихся фаз практической и познавательной деятельности» [8, с. 207-208], а также ориентирует субъекта в предметном и социальном мире. В целом, деятельность - это «процесс, осуществляющий одну из многообразных форм отношений человека к миру, особенность которого заключается в том, что то, на что направлена деятельность, есть в то же время, то что ее побуждает» [9, с. 152]

Практически жизнь человека - это система сменяющих друг друга деятельностей, в процессе жизнедеятельности и профессиональной деятельности, раскрывающая динамику взаимосвязей между полюсами субъект-объект. Важнейшим условием эффективного взаимодействия субъекта труда с объективной реальностью в процессе исполнения профессиональной деятельности «является ориентировка первого во втором» [10, с. 158]. На разных этапах развития благодаря деятельности у человека формируются новые взаимосвязи с объективной реальностью: изменяется ее восприятие, отношение к окружающему миру и событиям, расширяется «картина мира», приобретается опыт преодоления противоречий, расширяется ориентировочная основа жизнедеятельности и профессиональной деятельности, формируются индивидуальные стратегии деятельности и поведения. «В деятельности, поскольку она остается и будет оставаться творческой по своей природе, всегда остается и будет оставаться момент неожиданности, неоднозначности выбора, неполноты наличного знания, воздействия ценностных, нравственных, эстетических факторов, неосознаваемых мотивов и т. Д.» [7, с. 347].

С позиций методологии системного познания профессиональная деятельность является сложноорганизованным объектом, так как это специфическая форма активного отношения человека к окружающему миру и к конкретной профессиональной ситуации, представляющая собой сложное взаимодействие субъективного и объективного, предпосылки формирования которого начинаются с момента «вхождения» человека в реальную жизнь.

Вышеизложенные научные позиции являются основополагающими для определения психологических механизмов регуляции профессиональной деятельности и поведения индивидуального субъекта труда, обусловливающими эффективность его работы. 
С этих позиций работа персонала в организации рассматривается как деятельность, обусловленная индивидуальной потребностью, личностной направленностью, уровнем психического развития, функциональными возможностями организма во взаимосвязи с объективной реальностью (конкретной ситуацией, условиями и средой).

В контексте настоящей работы исходной точкой определения психологических механизмов регуляции профессиональной деятельности является объективно существующая данность взаимосвязи развития человека как личности и субъекта труда с постоянно происходящими изменениями окружающей его реальности и необходимость формирования ориентировки в ней, так как это предопределяет его психологическую готовность к различным переменам и является одним из важнейших механизмов эмоционально-волевой регуляции функционирования базовых психических процессов, обеспечивающих эффективность деятельности субъекта труда в организации. Основываясь на деятельностном подходе и анализе теоретических и экспериментальных работ известных отечественных и зарубежных ученых (Б. Г. Ананьева, Дж. Брунера, А. В. Брушлинского, Л. С. Выготского, П. Я. Гальперина, Е. А. Климова, А. Н. Леонтьева, В. Н. Мясищева, И. М. Сеченова, С. Л. Рубинштейна, Э. Фромма, Д. Б. Эльконина, Э. Эриксона и др.) гипотетически была выделена познавательная деятельность, как базовая единица изучения психологических механизмов регуляции деятельности субъекта труда и ее структура [11; 12]. Структура познавательной деятельности включает все психические сферы жизнедеятельности человека: чувственно-эмоциональную, потребностно-мотивационную, ценностно-смысловую, коммуникативно-социальную, операционально-ориентировочную, когнитивно-образную, мотивационно-эмоциональную и регуляторно-волевую, взаимосвязанное функционирование которых, в значительной мере, обусловливает эффективность деятельности на всех этапах формирования личности и субъекта труда.

Обоснованность выделения познавательной деятельности как базовой единицы определения психологических механизмов регуляции эффективности профессиональной деятельности заключается в том, что, с одной стороны, она раскрывает продуктивную активность формирования человека как лич- ности и субъекта труда на протяжении всех периодов онтогенетического развития и позволяет изучать иерархические взаимосвязи основных механизмов психической регуляции человека на всех этапах его жизнедеятельности и профессиональной деятельности в разные периоды профессионального становления [11]. С другой, - что успешность, эффективность и жизнестойкость человека, в определенной мере, предопределена его позитивной, продуктивной познавательной направленностью, обеспечивающей ему не только способность ориентироваться в окружающем мире, жизненном и профессиональном, но и развивая себя расширять и преобразовывать осмысление этого мира и более продуктивно осваивать перемены [13].

C позиций системно-деятельностного подхода познавательная деятельность рассматривается как развивающаяся динамическая полисистема, как сложный динамический процесс, интегрирующий и активизирующий все психические сферы, обеспечивающие формирование индивидуальной стратегии психологического и профессионального развития, а также и самосовершенствования человека во взаимосвязи с объективными условиями и профессиональной средой исполнения деятельности. Познавательная деятельность способствует развитию человека на всех этапах его жизненного и профессионального пути: дошкольном, школьном, учебно-профессиональном и профессиональном. Динамику ее преобразования можно изучать, по трем последовательно исполняемым фазам, ориентировочной, исполнительной и продуктивно преобразующей, в каждой из которых активизируются разные механизмы психической регуляции: когнитивно-образные, потребностно-мотивационные, ценностно-смысловые, чувственно-эмоциональные, операционально-ориентировочные, мотивационно-эмоциональные, регуляторно-волевые коммуникативно-социальные. Ориентировочная фаза позволяет выявить уровень сформированности и характер взаимосвязи когнитивно-образного, ценностно-смыслового, потребностно-мотивационного и регуляторного-волевого механизмов, предопределяющих успешность исполнительной фазы деятельности. В исполнительной фазе раскрывается уровень сформированности и характер взаимосвязей операционально-ориентировочных, коммуникативно-социальных, мотивационно-эмо- 
циональных, чувственно-эмоциональных и регуляторно-волевых механизмов, которые в совокупности предопределяют успешность и эффективность продуктивной преобразующей фазы деятельности, т. е. ее результат.

Данный подход к изучению, формированию и оценке сформированности психологических механизмов эффективности профессиональной деятельности можно рассматривать как ориентировочную основу совершенствования управления эффективностью труда персонала в организации. Изменения иерархических взаимосвязей компонентов структуры познавательной де- ятельности и их направленность, преобладание развития каких либо психических сфер и соответствие этого развития объективной ситуации в которой оказывается человек, доминирующая активизация различных психических сфер в разных фазах (ориентировочной, исполнительной и продуктивной преобразующей) осуществления деятельности на разных этапах профессионального становления, могут быть ориентирами и показателями для определения проекта и программы решения различных практических задач в целях повышения эффективности деятельности персонала в организации.

\section{Список использованной литературы}

1. Кирхлер Эрих. Психологические теории организации : пер. с нем. / Эрих Кирхлер, Катя Майер-Пести, Ева Хофман. - Харьков : Гуманитар. центр, 2005. - 308 с.

2. Майстер Дэвид. Истинный профессионализм : пер с англ. / Дэвид Майстер. - М. : Альпина Бизнес Букс, 2004. - 227 с.

3. Кови Стивен Р. Семь навыков высокоэффективных людей : пер. с англ. / Стивен Р. Кови. - М. : Альпина Бизнес Букс, 2006. - 374 с.

4. Рамперсад Хьюберт К. Универсальная система показателей деятельности : пер. с англ. / Хьюберт К. Рамперсад. - М. : Альпина Бизнес Букс, 2005. - 351с.

5. Асмолов А. Г. Принцип организации памяти человека. Системно-деятельностный подход к изучению познавательных процессов / А. Г. Асмолов. - М. : Изд-во МГУ, 1985. 165 c.

6. Кудрявцева Е. И. Психология управленческой эффективности в условиях распределенного управления / Е. И. Кудрявцева // Управленческое консультирование. - 2013. № 9 (57). - С. 22-32.

7. Юдин Э. Г. Системный подход и принцип деятельности / Э. Г. Юдин. - М. : Наука, 1978. -391 c.

8. Леонтьев А. Н. Психологические основы развития ребенка и обучения / А. Н. Леонтьев ; ред. Д. А. Леонтьев. - М. : Смысл, 2009. - 423 с.

9. Леонтьев А. Н. Деятельность. Сознание. Личность / А. Н. Леонтьев. - М. : Полит. лит., 1975. -303 с $335 \mathrm{c}$

10. Климов Е. А. Введение в психологию труда / Е. А. Климов. - М. : Академия, 2004. -

11. Иванова Е. М. К проблеме психологической готовности человека к жизни и профессиональной деятельности / Е. М. Иванова / С Социальные и гуманитарные науки на Дальнем Востоке. - 2012. - № 2 (34). - С. 53-61.

12. Иванова Е. М. Познавательная деятельность как условие самоопределения личности и профессионального становления / Е. М. Иванова // Социальные и гуманитарные науки на Дальнем Востоке. - 2013. - № 2 (38). - С. 36-45.

13. Иванова Е. М. Познавательная направленность личности как потенциальный ресурс преодоления жизненных кризисов / Е. М. Иванова // Социальные и гуманитарные науки на Дальнем Востоке. - 2014. - № 3 (43). - С. 20-30.

\section{References}

1. Kirchler Erich, Meier-Pesti Katja, Hofmann Eva. Menschenbilder in Organisationen. Wien, 2004. (Russ. ed.: Kirchler Erich, Meier-Pesti Katja, Hofmann Eva. Psikhologicheskie teorii organizatsii. Khar'kov, Gumanitarnyi tsentr Publ., 2005. 308 p.).

2. Maister David H. True Professionalism: The Courage to Care About Your People, Your Clients, and Your Career. New York, Free Press, 1999. 224 p. (Russ. ed.: Maister Devid. Istinnyi professionalizm. Moscow, Al'pina Biznes Buks Publ., 2004. 227 p.).

3. Kovi Stephen R. The 7 Habits of Highly Effective People: Restoring the Character Ethic. New York, Simon and Shuster, 1989. 368 p. (Russ. ed.: Kovi Stephen R. Sem' navykov vysokoeffektivnykh lyudei. Moscow, Al'pina Biznes Buks Publ., 2006. 374 p.). 
4. Rampersad Hubert K. Total Performance Scorecard: Redefining Management to Achieve Performance with Integrity. Amsterdam, Elsevier Science, 2003. 332 p. (Russ. ed.: Rampersad Hubert K. Universal'naya sistema pokazatelei deyatel'nosti. Moscow, Al'pina Biznes Buks Publ., 2005. 351 p.).

5. Asmolov A. G. Printsip organizatsii pamyati cheloveka. Sistemno-deyatel'nostnyi podkhod $k$ izucheniyu poznavatel'nykh protsessov [Principles of organization of human memory. System-activity approach to the study of cognitive processes]. Lomonosov Moscow State University Publ., 1985. $165 \mathrm{p}$.

6. Kudryavtseva E. I. Psychology of administrative efficiency in conditions of the distributed management. Upravlencheskoe konsul'tirovanie = Administrative Consulting, 2013, no. 9 (57), pp. 22-32. (In Russian).

7. Yudin E. G. Sistemnyi podkhod i printsip deyatel'nosti [Systems approach and principle of activity]. Moscow, Nauka Publ., 1978. 391 p.

8. Leont'ev A. N., Leont'ev D. A. (ed.). Psikhologicheskie osnovy razvitiya rebenka i obucheniya [Psychological basis of the child development and education]. Moscow, Smysl Publ., 2009. 423 p.

9. Leont'ev A. N. Deyatel'nost'. Soznanie. Lichnost' [Activity, consciousness, and personality]. Moscow, Politicheskaya literatura Publ., 1975. 303 p.

10. Klimov E. A. Vvedenie v psikhologiyu truda [Introduction to labour psychology]. Moscow, Akademiya Publ., 2004. 335 p.

11. Ivanova E. M. The problem of a person's psychological readiness for life and professional activity. Sotsial'nye i gumanitarnye nauki na Dal'nem Vostoke = The Humanities and Social Studies in the Far East, 2012, no. 2 (34), pp. 53-61. (In Russian).

12. Ivanova E. M. Cognitive activity as prerequisite for personal self-identification and professional growth. Sotsial'nye i gumanitarnye nauki na Dal'nem Vostoke = The Humanities and Social Studies in the Far East, 2013, no. 2 (38), pp. 36-45. (In Russian).

13. Ivanova E. M. Cognitive orientation of personality qua potential resource for overcoming life crises. Sotsial'nye i gumanitarnye nauki na Dal'nem Vostoke = The Humanities and Social Studies in the Far East, 2014, no. 3 (43), pp. 20-30. (In Russian).

\section{Информация об авторе}

Иванова Елена Михайловна - доктор психологических наук, доцент, факультет психологии, Московский государственный университет им. М. В. Ломоносова, 125009, Российская Федерация, г. Москва, ул. Моховая, 11, стр. 5, е-mail: e.m.ivanova@ mail.ru.

\section{Библиографическое описание статьи}

Иванова Е. М. О психологических механизмах повышения эффективности деятельности персонала в организации / Е. М. Иванова / / Психология в экономике и управлении. - 2016. T. 8, № 1-2. - C. 43-50. - DOI : 10.17150/22257845.2016.8(1-2).43-50.

\section{Author info}

Ivanova, Elena M. - Doctor of Psychology, Associate Professor, Department of Psychology, Lomonosov Moscow State University, 11/5 Mokhovaya St., 125009, Moscow, Russian Federation, e-mail: e.m.ivanova@ mail.ru.

\section{Reference to article}

Ivanova E. M. About the psychologic mechanisms of the effectiveness improvement of the corporate staff. Psikhologiya $v$ ekonomike $i$ upravlenii $=$ Psychology in Economics and Management, 2016, vol. 8, no. 1-2, pp. 43-50. DOI: 10.17150/2225-7845.2016.8(1-2).43-50. (In Russian). 